\title{
Importance of immunoglobulin therapy for COVID-19 patients with lymphocytopenia
}

Heba K. Nabih* ${ }^{*}$

\begin{abstract}
Background: The global coronavirus disease 2019 (COVID-19) was announced as pandemic by the World Health Organization (WHO). With the increased number of infected and dead victims daily all over the world, it becomes necessary to stop or overcome its rapid spread.

Main body

Although the production of vaccine or even specified effective anti-virus may take about six months to a year, intravenous immunoglobulin (IVlg) may be clinically used as a safe treatment to save and improve the quality of life of patients with a variety of immunodeficiency diseases such as lymphocytopenia, which is a common clinical feature in COVID-19.

Conclusion: Through the current review, it was concluded that this passive immunization may promote the immunity to better fight against the virus, so the survival of the patients could be kept longer. The efficacy of immunotherapy with IVIg would be greater if the immune IgG antibodies were collected from convalescent plasma therapy.
\end{abstract}

Keywords: COVID-19, Lymphocytopenia, Immunoglobulins, Immunotherapy, Passive immunization, Convalescent plasma therapy

\section{Background}

The epidemic of severe acute respiratory syndrome coronavirus 2 (SARS-CoV-2) originating in Wuhan, China, has rapidly spread all over the world (Huang et al. 2020), and in March 2020, the World Health Organization (WHO) declared coronavirus disease 2019 (COVID19) (SARS-CoV-2) outbreak a pandemic (World Health Organization (WHO) 2020).

\section{Main text}

\section{Incidence of lymphocytopenia in COVID-19 patients}

One of the most common clinical features of patients suffering from novel coronavirus disease 2019 (COVID-19) is lymphocytopenia. Such a decrease of lymphocytes in

\footnotetext{
*Correspondence: dr_heba_kamal@hotmail.com; hk.hanafi@nrc.sci.eg; hk.nabih@nrc.sci.eg

Medical Biochemistry Department, Medical Research Division, National Research Centre, 33 El Bohouth St. (Former El Tahrir St.), Dokki, P.O. 12622, Giza, Egypt
}

many cases may indicate or lead to serious illness that can be fatal due to suppression of immunity that will result in severe risk complications due to increased facility of viral, bacterial, and fungal infections. In one screening study including 41 patients diagnosed with COVID-19, Huang et al. 2020 recorded that $26(63 \%)$ of 41 patients had lymphocytopenia ( $85 \%$ of an intensive care unit (ICU) patients and $54 \%$ of non-ICU patients). Thirteen (32\%) patients were admitted to ICU and six (15\%) died. Compared with non-ICU patients, ICU patients had higher plasma levels of interleukins (ILs)-2, 7, 10, granulocytemacrophage colony-stimulating factor (GM-CSF), and tumor necrosis factor alpha (TNF- $\alpha$ ) (Huang et al. 2020).

\section{Immunoglobulins and their production}

Immunoglobulins (Igs) are highly diverse autologous molecules able to improve the immunity in different physiological and diseased conditions. They have a role in the development and function of both $\mathrm{B}$ and $\mathrm{T}$ lymphocytes. Deficiencies in either of these two arms of 
immunity can result in a heightened susceptibility to bacterial, fungal, or viral infections. Immunoglobulins are a group of closely related glycoproteins composed of $82-96 \%$ protein and $4-18 \%$ carbohydrate. The plasma concentration of these $150 \mathrm{kDa}$ glycoproteins is depending on individual variations and level of environmental exposure to antigens, with a mean concentration of 7 to $12 \mathrm{~g} / \mathrm{L}$. The immunoglobulin G (IgG), a major effector molecule of the humoral immune response, accounts for about $75 \%$ of the total Igs in the plasma of healthy individuals. Other classes of Igs which constitute the other $25 \%$ of the Igs are IgM, IgA, IgD, and IgE (Afonso and João 2016).

Polyclonal immunoglobulins may be used as a therapy in many diseases in different circumstances such as primary and secondary hypogammaglobulinemia, recurrent infections, polyneuropathies, cancer, and after allogeneic transplantation. Moreover, polyclonal immunoglobulins were reported to activate certain subpopulations of $\mathrm{T}$ cells with effects on $\mathrm{T}$ cell proliferation, survival, and function in lymphocytopenia, a situation that is accompanied by hypogammaglobulinemia. These results confirm the impact of intravenous immunoglobulin (IVIg) treatment as a therapy in cases of severe lymphocytopenia, a situation that can occur after chemo- and radiotherapy treatments of cancer patients with or without COVID-19 infection. Besides, IVIg has also been used as an anti-infectious agent against viruses, bacteria, and fungi in human patients and experimental models (Diep et al. 2016; Bayry et al. 2004; Shopsin et al. 2016; BenNathan et al. 2003). IVIgs are a therapeutic preparation of pooled normal polyspecific human IgGs collected from large numbers of healthy donors. The preparation contains antibodies to microbial antigens, self-antigens (natural auto-antibodies), and anti-idiotypic antibodies which recognize other antibodies. The many thousands of donors who contribute to a typical pool of plasma used for isolation of immunoglobulin represent a wide range of antibody specificities against infectious agents (Looney and Huggins 2006; Guideline and on the Clinical Investigation of Human NormalImmunoglobulin For Intravenous Administration (IVIg) 2014) such as bacterial, viral, and also a large number of self-antigens reflecting the cumulative exposure of the donor population to the environment. IVIg preparations from pooled plasma of thousands of healthy donors contain both monomeric IgG fraction that shows increased reactivity toward T-independent antigens of pathogens and dimeric IgG fraction that represents mainly idiotypic-anti-idiotypic antibody pairs and controls the immune response to certain categories of pathogens, whereas IVIg isolated from one donor contains only IgG monomers (Tankersley et al. 1988). Cohn et al. in cooperation with Oncley et al.
(Cohn et al. 1946; Oncley et al. 1949) found a method that yields Igs for intravenous and subcutaneous use (Eibl 2008) by the separation of plasma proteins into individual stable large-scale fractions with different biologic functions. The primary purification processes for commercial IVIg production include fractionation, purification (through removal of lipoproteins, albumin, and other plasma proteins, by cloth filtration in the presence of filter aid, a procedure that also removes many potential viruses (Buchacher and Iberer 2006)), ion-exchange chromatography (the implementation of chromatographic procedures also aims at the removal of IgA, a cause of severe anaphylactic shock in patients with IgA deficiency presenting anti-IgA antibodies), and virus inactivation and removal using solvent/detergent (S/D) treatment (Fahey and Horbett 1959). Pasteurization is used by some manufacturers to treat IVIg solutions by heating at 60 " $\mathrm{C}$ for $10 \mathrm{~h}$ (Uemura et al. 1994). A more recent method prepares the IgG more or less directly from plasma and not from a precipitate. Recently, the manufacturing processes have become more developed ensuring good in vivo tolerance and minimizing side effects, in particular transmission of infectious agents and facilitated recovery (Radosevich and Burnouf 2010; Martin 2006).

Depending on the immune status of the patient, the half-life of IVIg after intravenous infusion or intramuscular injection is about $2-3$ weeks. The half-life of most IgG antibodies is 33-36 days in immune-deficient patients who receive IVIg infusions, with a median serum halflife of 23 days (Wasserman et al. 2009). This increases the availability of sufficient specific IgG to fight infection. After injection of relatively high amounts of IVIg $(0.1-2 \mathrm{~g} / \mathrm{kg}$ body mass), the IgG concentration in serum immediately elevates, falls rapidly in the first 1 to 7 days (due to passage of IgG out of the vasculature into lymph and extracellular fluid compartments), and then falls more slowly thereafter (because of catabolism while IgG in lymph and tissues slowly diffuses back into the circulation) (Bonilla 2008).

\section{Impact of immunoglobulin therapy for COVID-19 patients}

IVIg has immunomodulatory activities such as decreasing self cellular destruction mediated by phagocytosis (Gelfand 2012), neutralizing an autoantibody and hampering its production via binding to auto-reactive B lymphocytes (Dwyer 1992), complement system inhibition to hamper the subsequent formation of the membrane attack complex (Basta 1996), modulation of cytokine including interleukins (ILs)-1, 2, 3, 4, 5, 10, tumor necrosis factor alpha (TNF- $\alpha$ ), and granulocyte-macrophage colony-stimulating factor (GM-CSF) and cytokine antagonist (IL-1 receptor antagonist) production (Andersson et al. 1996), impairing the ability of mature dendritic 
cells (DCs) to produce IL-12, and enhancing their ability to produce IL-10 (Bayry et al. 2003; Othy et al. 2012), preventing platelet consumption triggered by a pathogenic auto-antibody (Samuelsson et al. 2001), enhancing in glucocorticoid receptor-binding affinity, subsequently enhanced glucocorticoid sensitivity, and synergistic suppression of lymphocyte activation when combined with glucocorticoids (Spahn et al. 1999), and expanding of lymphocyte repertoire diversity to promote lymphocyte development and also to improve lymphocyte function (Pires et al. 2010). Additionally, IVIg therapy also led to increased expression of peroxisome proliferatoractivated receptor gamma (PPAR $\gamma$ ), a ligand-activated transcription factor that mediates anti-inflammatory functions and resolution of inflammation, but reduced Toll-like receptor 4 (TLR-4) expression, which mediates the inflammatory response (Jawhara 2020). All of these IVIg activates could help in enhancing production and improving function of lymphocytes, relieving the associated inflammations, and protecting cells of patients suffering from novel COVID-19.

Less than 5 percent of patients have adverse reactions to IVIg due to the aggregation forms of IgGs (Gelfand 2012; Bayry et al. 2003). Mild reactions to Igs can occur within the first $30 \mathrm{~min}$ after infusion and may be relieved by minimizing the infusion rate or temporarily stopping the infusion (Carbone 2007). Moreover, a number of clinical and experimental studies show that these adverse reactions can be reduced by subcutaneous administration of IVIg (Ochs et al. 2006; Markvardsen et al. 2013; Harbo et al. 2010).

\section{Convalescent plasma therapy for COVID-19 patients}

Immunotherapy with IVIg could be employed to neutralize COVID-19. However, the efficacy of IVIg would be better if the immune IgG antibodies were collected from patients who have recovered from COVID-19 (convalescent plasma therapy) in the same city, or the surrounding area (as these donor subjects have naturally been confronted with the virus), in order to increase the chance of neutralizing the virus (passive immunization) until stronger options such as vaccines that will may take long time to develop and test before it can be public or effective antiviral therapy against COVID-19 are available (Jawhara 2020). All donors have to be previously diagnosed with laboratory-confirmed COVID19 and subsequently tested negative for SARS-CoV-2 and other respiratory viruses, as well as for hepatitis $\mathrm{B}$ virus, hepatitis $C$ virus, HIV, and syphilis at the time of blood donation. In one case series, five patients who were critically ill with COVID-19 were treated with convalescent plasma. All plasma samples from the donors were detected to have high virus-specific IgG and IgM ELISA titers, antibodies. The results of this study lead to that convalescent plasma may have contributed to the clearance of the COVID-19 virus and also the improvement of symptoms (Shen et al. 2020).

\section{Conclusions}

Intravenous immunoglobulin (IVIg) therapy has saved and improved the quality of life of patients with a variety of immunodeficiency diseases such as lymphocytopenia, which is a common clinical feature in COVID-19. Despite an overall excellent safety record, IVIg can cause serious complications that may be minimized. The science must keep moving so that convalescent plasma, which is isolated from recently COVID-19-recovered survivors, should be collected. The immunoglobulins must be quickly characterized and then produced efficiently in large quantities through expert scientific companies and pharmaceutical manufacturers. These immunoglobulins are safe and effective against COVID-19 and will attenuate the fatal threat and keep life of COVID-19 patients.

\begin{abstract}
Abbreviations
COVID-19: Coronavirus disease 2019; WHO: World Health Organization; IVIg: Intravenous immunoglobulin; ICU: Intensive care unit; ILs: Interleukins; GM-CSF: Granulocyte-macrophage colony-stimulating factor; TNF-a: Tumor necrosis factor alpha; Igs: Immunoglobulins; IgG: Immunoglobulin G; S/D: Solvent/detergent; DCs: Dendritic cells; PPARY: Peroxisome proliferator-activated receptor gamma; TLR-4: Toll-like receptor 4.
\end{abstract}

\section{Acknowledgements \\ Not applicable.}

\section{Authors' contributions}

HK designed, drafted, and revised the manuscript. The author read and approved the final manuscript.

\section{Funding}

This review article did not receive any specific grant from funding agencies in the public, commercial, or not-for-profit sectors.

\section{Availability of supporting data \\ Not applicable.}

Ethical approval and consent to participate Not applicable.

\section{Consent for publication}

Not applicable.

Competing interests

The author declares no competing interests.

Received: 26 May 2020 Accepted: 10 February 2021

Published online: 22 February 2021

\author{
References \\ Afonso AFB, João CMP (2016) The production processes and biological effects \\ of intravenous immunoglobulin. Biomolecules 6: 15. doi:https://doi. \\ org/10.3390/biom6010015
}


Andersson J, Skansén-Saphir U, Sparrelid E, Andersson U (1996) Intravenous immune globulin affects cytokine production in T lymphocytes and monocytes/macrophages. ClinExplmmunol 104:10-20

Basta M (1996) Modulation of complement-mediated immune damage by intravenous immune globulin. ClinExplmmunol 104:21-25

Bayry J, Carbonneil C, Misra N, Donkova V, Pashov A, Chevailler A, Mouthon L, Weill B, Bruneval P, Kazatchkine MD, Kaveri SV (2003) Inhibition of maturation and function of dendritic cells by intravenous immunoglobulin. Blood 101:758-765

Bayry J, Lacroix-Desmazes S, Kazatchkine MD, Kaveri SV (2004) Intravenous immunoglobulin for infectious diseases: Back to the pre-antibiotic and passive prophylaxis era?. Trends Pharm Sci 25: 306-310

Ben-Nathan D, Lustig S, Tam G, Robinzon S, Segal S, Rager-Zisman B (2003) Prophylactic and therapeutic efficacy of human intravenous immunoglobulin in treating West Nile virus infection in mice. J Infect Dis 188:5-12

Bonilla FA (2008) Pharmacokinetics of immunoglobulin administered via intravenous or subcutaneous routes. Immunol Allergy Clin North Am 28:803-819

Buchacher A, Iberer G (2006) Purification of intravenous immunoglobulin $\mathrm{G}$ from human plasma: aspects of yield and virus safety. Biotechnol J 1:148-163

Carbone J (2007) Adverse reactions and pathogen safety of intravenous immunoglobulin. Curr Drug Saf 2:9-18

Cohn EJ, Strong LE, Hughes WL, Mulford DJ, Ashworth JN, Melin M, Taylor HL (1946) Preparation and properties of serum and plasma proteins; a system for the separation into fractions of the protein and lipoprotein components of biological tissues and fluids. J Am ChemSoc 68:459-475

Diep BA, Le VT, Badiou C, Le HN, Pinheiro MG, Duong AH, Wang X, Dip EC, Aguiar-Alves, F, Basuino L, Marbach H, Mai TT, Sarda MN, Kajikawa O, Matute-Bello G, Tkaczyk C, Rasigade JP, Sellman BR, Chambers HF, Lina G (2016) IVIG-mediated protection against necrotizing pneumonia caused by MRSA. Sci Transl Med 8: 357ra124

Dwyer JM (1992) Manipulating the immune system with immune globulin. N Engl J Med 326:107-116

Eibl MM (2008) History of immunoglobulin replacement. Immunol Allergy Clin North Am 28:737-764

European Medicines Agency Guideline on the Clinical Investigation of Human Normallmmunoglobulin For Intravenous Administration (IVlg) (2014) Available online: http://www.ema.europa.eu/docs/en_GB/docum ent_library/Scientific_guideline/2009/10/WC500004766.pdf. Accessed on 22 Aug 2014

Fahey UL, Horbett AP (1959) Human gamma globulin fractionation on anion exchange cellulose columns. J BiolChem 234:2645-2651

Gelfand EW (2012) Intravenous immune globulin in autoimmune and inflammatory diseases. N Engl J Med 367:2015-2025

Harbo T, Andersen H, Jakobsen J (2010) Long-term therapy with high doses of subcutaneous immunoglobulin in multifocal motor neuropathy. Neurology $75: 1377-1380$

Huang C, Wang Y, Li X, Ren L, Zhao J, Hu Y, Zhang L, Fan G, Xu J, Gu X, Cheng Z, Yu T, Xia J, Wei Y, Wu W, Xie X, Yin W, Li H, Liu M, Xiao Y, Gao H, Guo L, Xie J, Wang G, Jiang R, Gao Z, Jin Q, Wang J, Caohere B (2020) Clinical features of patients infected with 2019 novel coronavirus in Wuhan, China. Lancet 395: 497-506. 10.1016S0140-6736(20)30183-5

Jawhara S (2020): Could Intravenous Immunoglobulin Collected from Recovered Coronavirus Patients Protect against COVID-19 and Strengthen the Immune System of New Patients?. Int. J. Mol. Sci.; 21, 2272; doi:https://doi. org/10.3390/ijms21072272.
Looney RJ, Huggins J (2006) Use of intravenous immunoglobulin G (IVIG). Best Pract Res Clin Haematol 19: 3-25

Markvardsen LH, Debost JC, Harbo T, Sindrup SH, Andersen H, Christiansen I, Otto M, Olsen NK, Lassen LL, Jakobsen J et al (2013) Subcutaneous immunoglobulin in responders to intravenous therapy with chronic inflammatory demyelinating polyradiculoneuropathy. Eur J Neurol 20:836-842

Martin TD (2006) IGIV: contents, properties, and methods of industrial production: evolving closer to a more physiologic product. Intlmmunopharmacol 6:517-522

Ochs, H.D.; Gupta, S.; Kiessling, P.; Nicolay, U.; Berger, M.; Subcutaneous Ig, G.S.G. Safety and efficacy of self-administered subcutaneous immunoglobulin in patients with primary immunodeficiency diseases. J. Clin. Immunol. 2006, 26, 265-273.

Oncley JL, Melin M, Richert DA, Cameron JW, Gross PM (1949) The separation of the antibodies, isoagglutinins, prothrombin, plasminogen and $\beta 1$-lipoprotein into subfractions of human plasma. J Am ChemSoc 71:541-550

Othy S, Bruneval P, Topçu S, Dugail I, Delers F, Lacroix-Desmazes S, Bayry J, Kaveri SV (2012) Effect of IVIg on human dendritic cell-mediated antigen uptake and presentation: role of lipid accumulation. J Autoimmun 39:168-172

Pires A, Afonso A, Queirós A, Cabral M, Porrata L, Markovic S, Kaveri S, da Silva M, João C (2010) Treatment with polyclonal immunoglobulin during T-cell reconstitution promotes naive T-cell proliferation. J Immunother 33:618-625

Radosevich M, BurnoufT (2010) Intravenous immunoglobulin G: Trends in production methods, quality control and quality assurance. Vox Sang 98:12-28

Samuelsson A, Towers TL, Ravetch JV (2001) Anti-inflammatory activity of IVIG mediated through the inhibitory Fc receptor. Science 291:484-486

Shen C, Wang Z, Zhao F, et al. Treatment of 5 Critically III Patients With COVID19 With Convalescent Plasma. JAMA. Published online March 27, 2020. doi:https://doi.org/10.1001/jama.2020.4783

Shopsin B, Kaveri SV, Bayry J (2016) Tackling difficult Staphylococcus aureus infections: antibodies show the way. Cell Host Microbe 20:555-557

Spahn JD, Leung DY, Chan MT, Szefler SJ, Gelfand EW (1999) Mechanisms of glucocorticoid reduction in asthmatic subjects treated with intravenous immunoglobulin. J Allergy Clinlmmunol 103:421-426

Tankersley DL, Preston MS, Finlayson JS (1988) Immunoglobulin G dimer: an idiotype-anti-idiotype complex. Mollmmunol 25:41-48

Uemura Y, Yang YH, Heldebrant CM, Takechi K, Yokoyama K (1994) Inactivation and elimination of viruses during preparation of human intravenous immunoglobulin. Vox Sang 67:246-254

Wasserman RL, Church JA, Peter HH, Sleasman JW, Melamed I, Stein MR, Bichler $J$ (2009) Pharmacokinetics of a new 10\% intravenous immunoglobulin in patients receiving replacement therapy for primary immunodeficiency. Eur J Pharm Sci 37:272-278

World Health Organization (WHO) (2020) Novel coronavirus (COVID-19) situation. Updated in 5th April, 2020. https://www.who.int/emergencies/disea ses/novel-coronavirus-2019

\section{Publisher's Note}

Springer Nature remains neutral with regard to jurisdictional claims in published maps and institutional affiliations. 